\title{
RELATIONSHIP BETWEEN JOINT MASTERY AT ONE HAND AND THE ANTHROPOMETRIC, KINEMATIC AND STABILOGRAPHIC CHARACTERISTICS OF SELECTED SPORTS TECHNIQUES IN SHOTOKAN-KARATE
}

\author{
Dimitar Zagorsky, Maria Gikova, Ognian Tishinov
}

\author{
National Sports Academy "Vassil Levski" \\ Key words: kinanthropometry, biokinematic analysis, Shotokan-Karate

\section{Introduction} \\ Shotokan is a martial art requiring strength and coordination. Anthropometric characteristics and mor- \\ phological indicators are essential in assessing athlete's achievements for Keogh J. (1999), Wilmore J.H.
}

and Costill D.L. (1999). Physical parameters such as body composition, size, type and structure are considered key factors for excellence in various sport events (kinanthropometry).

Compared to the general population, Karate players are characterized by a morphological complex optimized for achieving the best results in martial arts: an emphasized higher percentage of muscle mass relative to a higher height and optimal adipose tissue depots. According to Katic R.'s team (2005), disproportionate physics with emphasized extremities musculature is characteristic of the elite Karatekas.

Apart from the morphological parameters the effectiveness of a fighting technique depends on the correct trajectory and speed of the movement. Our own team-Gikova M., Zagorsky D. and Tishinov O. (2013), has proven that through analysis of this kinematic characteristics an indirect assessment of the skeletal-muscular system is allowed [6]. The execution and duration of the impact, as well as the kinematics of the lower extremities, are of particular importance for the performance of a Shotokan Karate athlete.

According to Claessens A. et al. (1987), the relationship between body structure and its function is very important and representative of the opponent status in elite sport bouts. Two teams are working in this direction: Katic R.(2005), and Kopanovski N. (2011), proving that Karate training leads to the adjustment of the morphological sub-segment in the anthropological complex, optimizing the physique according to the requirements of the specific sport. Based on the distinctive set of motor tech- niques with their kinematic and kinetic models, distinct anthropometric and physical performance profiles will be developed in elite Karate athletes. Such a position is justified by the requirement for the development of motor skills (techniques) in karate and their effective use in combat, to undergo long-term and exhaustive training. That is the point that reasons the need for Karatekas to undergo long-term and exhaustive training as a requirement for the development of specific motor skills (techniques) effective in combat conditions.

Based on the findings of Arriaza R.s (2005), and Jovanovic S.s (2002), teams, blows with upper extremity are more natural than kicks-they are faster, easier to control, more difficult to block or avoid, which easily explains why they are more commonly used in Karate bouts then kicks. Therefore, the choice of both researchers: Pozo J. (2011), and Gianino C. (2010), are focused on kinematic analysis of the skills at performing Karate techniques, and specifically on the ability to execute a high-velocity kick, will be note-worthy precisely because of the inherited deficiencies and the ability of a highly trained competitor to turn a technique based more on disadvantage to his advantage while competing.

\section{Aim of the study}

The aim of this study was to reveal the relationship between morphological parameters and technique effectiveness compared to the fighting proficiency and acquired degree of the experimental group of elite Karate-Shotokan athletes through specialised measurement equipment and methods and subsequent trajectory and velocity analysis of the selected techniques. 


\section{Methods:}

Using derivate indicators of body composition (body mass, active body weight/percentage of muscle mass, body mass index (BMI), body fat percentage, index of fat around the internal organs, assessed general physical condition, bone mass, basic metabolism and metabolic age) determined by analyzer of body composition (Tanita BC-533). Anthropometry: Leicester measuring ruler used for measuring linear dimensions $(\mathrm{cm})$ with a maximum height of 2.0 meters. Description of the measured morphological parameters can be found in our previous work.

Kinematics Analysis: Shot with high-speed CASIO-EX-ZR200 video camera recording in frequency mode of $120 \mathrm{fps}$ and consecutive framing procession for obtaining kinematic parameters using SkilSpector software. The experimental group is of 18 athletes executing Gyako-Zuki punch with upper extremity, Mae-Geri straight front kick and Yoko-Geri side kick.

Variance and correlation analysis of the results was made with the statistical software package SPSS v.19

\section{Results and analysis:}

In determining the dependencies between anthropometric indicators according to the athletic proficiency, two groups were selected: 9 highly qualified ath- letes from I Dan and up, and second group with little sports practice and lower qualifications (1-3 Kyu). As means to represent in percentage the distribution between our Karate competitors based on qualification's profile a pie diagram is shown in Fig. 1

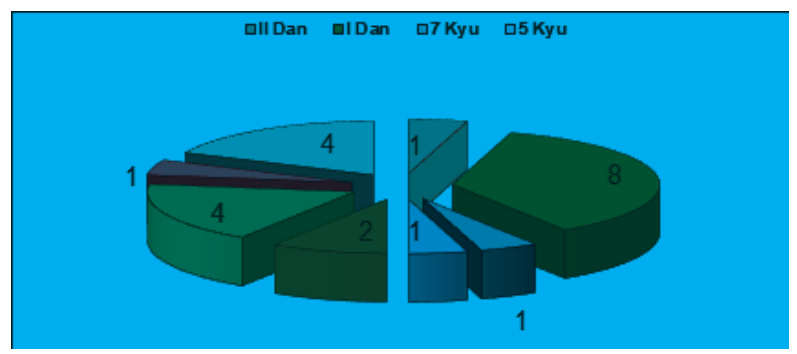

Figure 1. Visual representation of the athletic ranking in the experimental group, based on the Dan-Kyu system;

Once again, it is remarkable that the sample contains a high percentage of high class I and II Dan competitors (41\%), followed by the same percentage of the 1-3 Kyu group, illustrating once again the predominance of high qualification Karate athletes. The remark in the above lines about the lack of prominent effect of age as factor between the two groups and the forming of very well-tuned high and athletic contestants in the group participating in international and national championships comes from precisely those $82 \%$ highly profiled Karatekas according to the Kyu-Dan system

Table 1. Average values of derived anthropometric parameters of both high- and low-ranking athletes:

\begin{tabular}{|c|c|c|c|c|c|c|c|c|c|c|c|}
\hline $\begin{array}{c}\text { Dan-Kyu } \\
\text { ranking }\end{array}$ & $\begin{array}{c}\text { Years of } \\
\text { practice }\end{array}$ & $\begin{array}{c}\text { Height } \\
(\mathrm{cm})\end{array}$ & $\begin{array}{c}\text { Weight } \\
(\mathrm{Kg})\end{array}$ & BMI & $\begin{array}{c}\text { Water } \\
\text { content } \\
(\%)\end{array}$ & $\begin{array}{c}\text { Adipose } \\
\text { tissue } \\
(\%)\end{array}$ & $\begin{array}{c}\text { Visc. } \\
\text { Adipose } \\
\text { deposite }\end{array}$ & $\begin{array}{c}\text { Muscle } \\
\text { mass } \\
(\mathrm{Kg})\end{array}$ & OPFI & $\begin{array}{c}\text { Bone } \\
\text { mass } \\
(\mathrm{Kg})\end{array}$ & $\begin{array}{c}\text { Metabol- } \\
\text { ic rate } \\
(\mathrm{Kcal})\end{array}$ \\
\hline 3-1 Kyu & 10 & 165,33 & 67,7 & 24,28 & 59,04 & 17,18 & 1 & 23,34 & 5,4 & 2,8 & 1684 \\
\hline I-II Dan & 14,5 & 170 & 75,1 & 24,6 & 59,74 & 14,26 & 2,8 & 28,54 & 5,8 & 3,28 & 1937 \\
\hline
\end{tabular}

For the I Dan and above group, the average value of athletic qualification is 14.5 years, and for the low-qualified is of 10 years, based on calculated average for the traineeship.

It should be noted that in Karate athletes abnormally high levels of BMI are explained by the increased amount of muscle mass rather than accounting for larger amounts of adipose tissue. Differences are revealed too in the weight parameters: elite Karateks score $28.5 \mathrm{~kg}$ compared to $23.3 \mathrm{~kg}$ muscle mass for less-experienced athletes, which is not surprising taking into account a higher average height of 1.70 $\mathrm{m}$ versus $1.65 \mathrm{~m}$ at the average, when body weight is also in favor of the elite group: $75 \mathrm{~kg}$ compared to 68 $\mathrm{kg}$. It is also noteworthy the additional similarities in both groups: we have a Body Mass Index (BMI) oriented around 24 both, and a practically uniform body water content: 59.04 vs. $59.74 \%$, showing a balanced body composition. Compared to the studies of Stepkowitz-Przybycien K.L. team (2010), the BMI for Polish Karatekas varies between 20 and 30 $\mathrm{kg} / \mathrm{m} 2$ (22.9 to $31.0 \mathrm{~kg} / \mathrm{m} 2$ ), with adipose content between 12.9 and $20.8 \%$. And in their experimen- 
tal group, although international class participants scored mean BMI values higher than $25 \mathrm{~kg} / \mathrm{m} 2$ (24.8-28.8, supposedly overweight) compared to the novice group (students) where BMI was in the range of 25,12 of the elite and 6 of the national contestants score $B M I \geq 25 \mathrm{~kg} / \mathrm{m} 2$, precisely because of the high percentage of muscle mass (\% MM).

It is logical that with a reduced body fat content, high-level fighters will be less physically burdened by this passive component (only $14.3 \%$ compared to the $17.2 \%$ adipose tissue for the novice Karate competitors), from where and the Overall Physical Fitness Index (OPFI) will be higher (5.8 vs. 5.4 for lower class competitors). It is noteworthy that the values of some of the measured parameters are relatively close - especially the average age: for lower ranking competitors, its median is 21.7 years, ranging from 19 to 27 years, while high profile athletes with over 10 years of athletic experience also mark close: the average age is 22.3 years, and is in a similar range 19-29 years. Yet, a simple analysis of this age difference shows us that the elite Karatekas begin their training in childhood, while in the lower-class this is at the beginning of puberty. Age changes between the two groups do not have the same gravity and as result produce better fit, high and athletic players in the group participating in international and national championships.

The findings once again confirm the expected changes in the body composition of long-time and successful competitors in martial arts, and Karate in particular, leading to an optimized and balanced for speed, power and endurance body type. Based on multiple studies, proximal-distal muscle activation during a Karate strike is considered a factor in enhancing effective achievement of high movement velocity and power generation. The aimed analysis shows that when the agonist and antagonist muscles are simultaneously used, better movement control and stabilization of the joint are achieved.

Within our own experiments we drew the average value for punch measured at impact of $13.2 \mathrm{~m} / \mathrm{s}$, with the range of velocity variating within the sample between $5.1 \mathrm{~m} / \mathrm{s}$ to $21.2 \mathrm{~m} / \mathrm{s}$. Those values do not differ from Gianino's experiments, whose experimental terminal punch speed before contact was also 13 $\mathrm{m} / \mathrm{s}$, with the marginal acceleration of the forearm and fist having a uniform acceleration of $63 \mathrm{~m} / \mathrm{s}$ [5]. As expected among our own expreriment sub- jects, the highest values of $16.1 \mathrm{~m} / \mathrm{s}$ were developed by high qualification competitors, and especially among I Dan specialists. The above-mentioned values of literary review and within our own experience suggest that the so-called „close-to-distant" activation of multiple muscule groups starting from lower extremity and rising to the upper extremity in the executed punch not only provides the condition for generating effective force but also the achievement of necessary acceleration and terminal velocity as to execute a successful attack with upper extremity.

Again, it is remarkable that in our own Karate athletes there is almost a fourfold velocity differential when inexperienced fighters with only a 1-2 year combat training are compared to the most rigorous black belts, once again bringing fore the achievment of effective body control and execution of fast and powerful techniques by athletes who have a longer and more successful career.

So far, few studies have focused specifically on the analysis of lower extremity movements in Karate. The Belgian scientists, in the face of Poso J. at al., turn their attention to the kinetics in the hip and knee joints and the activity of Mai-Geri knee flexor/extensor muscles, aiming to determine adaptation of neuromuscular control in elite Karate athletes in this particular front kick. With respect to the Mai-Geri stand-alone technique, the study points out: international athletes are expected to perform a Mai-Geri kick in a shorter time, with greater impact force and a higher repeatability of kinetics and kinematics of lower extremity than athletes at national level, although there was no significant difference in the maximum impact of the kick between the two groups.

Based on his study, Gianino C. gives us an effective velocity of the foot before impact of the phenomenal $19 \mathrm{~m} / \mathrm{s}$, emphasizing on extraordinary acceleration of the thigh by hip joint muscles up to $108 \mathrm{~m} /$ sec2 and of the lower leg resulting from the thigh and calf muscles up to $78 \mathrm{~m} / \mathrm{sec}^{2}$. Due to the already mentioned delay mechanism in the Mai-Geri kick (in order not to consciously hurt the opponent), this disproportion between the acceleration of the thigh from the muscles around hip joint and the reached acceleration of the knee joint is expected and can be explained. It is noteworthy that in our elite Karate competitors, the Mai-Geri kick is executed at a lower average velocity of $12.3 \mathrm{~m} / \mathrm{s}$, with a 
maximum and minimum values of 6.8 to $19.8 \mathrm{~m} / \mathrm{s}$. What is noticeable is that the reached lower extremity velocity ranges from those closest to those of Gianino for our elite athletes, up to three times lower for the less experienced competitors (inevitable consequence of better control and effective use of body segments and their acceleration in order to reach the opponent faster yet still controlled).

Practical experience shows that the side directed Yoko-Geri kick, whether through ejection, coming from the knee or thigh, is very difficult to execute in combat conditions, mainly due to: the complexity of movements and consecutive intramuscular coordination, the limitations in flexibility of hip, knee and ankle joints, limited flexibility or particular weakness in lower extremity muscles (both ad- and ab-ductors) and those of abdominal wall. According to Feld M.S. and his team (1979), YokoGeri's average speed is in the range of 9.9-14 m/s with two phases: of thigh acceleration to Hiki Ashi position reaching to a "coiled“ state of lower extremity muscles, and then Yoko-Geri Kekomi „ejection" movement through launch of the leg and foot attached to it as the striking surface. According to Giannino C., terminal foot acceleration decreases due to the two-phase technique described above, reaching the effective $2 \mathrm{~m} / \mathrm{s}$ in the phase immediately before impact. In our experiment, Yoko-Geri's average kicks were $10.9 \mathrm{~m} / \mathrm{s}$, with a range of maximum and minimum values from 6.7 to $18.1 \mathrm{~m} / \mathrm{s}$. What is unique in our experiment is the already highlighted predominance of high-ranked athletes in the DanKyu system, resulting both the inferior velocity values for the inexperienced and slower Karatekas with low Kyu and the superior values for our elite athletes at $18 \mathrm{~m} / \mathrm{s}$ compared to Feld's kick speed.

Table 4 shows the characteristic impact velocity values and the angle at which this value is achieved for Gyaku-Zuki's punch, Mai-Geri and Yoko-Geri kicks by our competitors. Low values of variation, asymmetry and excess coefficients allow us to assume a normal distribution of the experimental data values for the studied statistical sample. The research we conducted yields results that are close to the comparative literature sources, yet the average values of fluctuation in the achieved angles for each of the three techniques in our study group are lesser, which is acceptable due to the lower qualification level by our inexperienced fighters.

Table 2. Average velocity and effective angles values in the execution of Gyaku-Zuki punch and Mae-Geri and Yoko-Geri kicks by Bulgarian Karate athletes;

\begin{tabular}{|c|c|c|c|c|c|}
\hline $\begin{array}{c}\text { Individual } \\
\text { technique }\end{array}$ & V Gyaku-Zuki & V Mai-Geri & V Yoko-Geri & $\begin{array}{c}\text { Angle } \\
\text { Mai-Geri }\end{array}$ & $\begin{array}{c}\text { Angle } \\
\text { Yoko-Geri }\end{array}$ \\
\hline $\mathbf{X}$ & 13,2 & 12,3 & 10,9 & 70,8 & 64,0 \\
\hline $\mathbf{S}$ & 3,6 & 3,6 & 4,1 & 13,2 & 13,9 \\
\hline $\mathbf{V}$ & $27 \%$ & $29 \%$ & $38 \%$ & $19 \%$ & $22 \%$ \\
\hline As & $-0,1$ & 0,0 & 1,9 & 0,2 & $-0,2$ \\
\hline Ex & 0,6 & $-0,7$ & 5,3 & $-1,4$ & $-0,6$ \\
\hline Max & 21,2 & 19,8 & 24,8 & 94,0 & 89,0 \\
\hline Min & 5,1 & 6,8 & 6,7 & 53,0 & 38,0 \\
\hline $\mathbf{R}$ & 16,1 & 13,0 & 18,1 & 41,0 & 51,0 \\
\hline
\end{tabular}

Table 3. Experimental average velocity values in execution of strikes with upper and lower extremity by elite athletes

\begin{tabular}{|c|c|c|c|}
\hline & V Gyaku-Zuki & V Mai-Geri & V Yoko-Geri \\
\hline average & 14,0 & 12,0 & 9,5 \\
\hline $\max$ & 21,2 & 16,8 & 12,8 \\
\hline $\min$ & 9,9 & 6,8 & 6,8 \\
\hline
\end{tabular}


The highest number of athletes are those of I Dan, whose average speed of Gyaku-Zuki is within 14 $\mathrm{m} / \mathrm{s}$ and ranges from 9.9 to $21.2 \mathrm{~m} / \mathrm{s}$, while kicks with lower extremity the average speed of Mae-Geri respectively falls down to $12 \mathrm{~m} / \mathrm{s}$, ranging from 6.8 to $16.8 \mathrm{~m} / \mathrm{s}$, and marks the lowest mean value for Yoko-Geri kick at $9.5 \mathrm{~m} / \mathrm{s}$ in the range between 6.8 to $12.8 \mathrm{~m} / \mathrm{s}$. Several dependencies are seen after the primary analysis: Gyaku-Zuki's right-hand punch creates the most heterogeneous group, but also with the highest absolute velocity-factor we have already drawn attention to, for which the difference from the slowest to the fastest fighters is over 2 times. This trend is not only preserved, but also enhanced in the next Mae-Geri straight-kick, in which although the average terminal velocity is lower, has the largest intra-group variance - our best fighters of national and international rank are more than 2.4 times faster compared to their slower counterparts from the I Dan and higher qualification group. In this subgroup we find another feature - the performance of the slowest of the executing straight-kick Elite Karate athletes is even inferior to that of the more unexperienced competitors (in the encoding of biometric measures we find that those are the heaviest and with a highest BMI and percent adipose fighters).

Because of the mentioned "charging" and "ejection" features of muscle contraction as two separate and demanding phases, it is not surprising that even by the high-ranking Karate athletes Yoko-Geri Kekomi is one of the most smoothly executed kicks: the execution speeds does not reach the target limit of 2 times faster performance among the fastest and most successful athletes from the elite Karatekas, to the extent that even the slowest Gyaku-Zuki punch is faster than the average executed Yoko-Geri. The interpretation of those differences has already been extensively dealt with in the mechanics behind the two strikes, and yet: the side kick contrasts not only based on the expediency of its performance but also on the experimental results and proves its intricacy, from where we can assume its values to be an example of the mastery of body's muscle synergy and balance in our Elite Karate athletes. This aproach will be particularly informative when applied to our lower-ranked and less experienced competitors:

Table 4. Experimental average velocity values in execution of strikes with upper and lower extremity by low-ranking athletes;

\begin{tabular}{|l|l|l|l|}
\hline & V Gyaku-Zuki & V Mai-Geri & V Yoko-Geri \\
\hline average & 10,4 & 10,6 & 9,1 \\
\hline Max & 17,0 & 14,3 & 13,4 \\
\hline Min & 5,1 & 7,4 & 6,8 \\
\hline
\end{tabular}

Here, for competitors of and below the $3 \mathrm{Kyu}$, who participated in our experiment, the results were expected to be inferior: lower average values are observed (most pronounced in the drop of 30\% to $10.4 \mathrm{~m} / \mathrm{s}$ for the Gyaku -Zuki punch, and with a evening out of the average velocity of arm and leg strikes), lowered maximum values compared to elevated minimums for the sample range which is fully understandable from the point of view based on the qualification level. Again most impressive is our most representative in combat practice Gyaku-Zuki punch: variation in velocity range from the slowest to the fastest more than 3.4 times - on its own this is a huge difference marking the measure of the muscle control in the event of a stimuli, and as such can not only help for unveiling deficiencies in performance of the more unexperienced fighters, but also competitors with greater readiness for rapid attack or effective counter-attack to stand out when screening for higher qualification level athletes.

Within the experimental data stands out the evening of the average velocity of the two kicks: the presented as direct and rapid forward strike of Mai-Geri and the more complicated side motion Yoko-Geri, even further- reaching paradox leveling among the slowest and less experienced low-rank athletes when executing those two strikes, up to a moment when Yoko-Geri kick becomes even faster (13.4 vs. $12.8 \mathrm{~m} / \mathrm{s}$ Mai-Geri). At one hand, part of the results can be explained by fighting style choice of the already well-practiced athletes who spend a small part of their time maintaining their readiness to perform swift and accurate side-kicks, while on the other is the fact that the novices are still not that specialized and as they seem-to be able to control at the limit of their capabilities the execution of both kicks! An additional aspect is that the slowest among the elite Karatekas are the heaviest and with the highest BMI, so lifting the leg to Hiki Ashi will be inevitably more difficult and therefore slower.

This readiness of the muscles to perform specific techniques and controlled recoil time are some of the most marked indicators that distinguish high qualification Karate athletes from those with less than 9 years of experience.

\section{Conclusion:}

Based on the analyzed anthropometric parameters is confermed that the elite Bulgarian Karate athletes exibit the expected body composition modifica- 
tions/alterations: long-time and successful athletes in combat sports are with body type optimized for balance between speed, strength and endurance. Our measurements of the chosen techniques produce relatively closer to international fighter's results, although the average speeds achieved for each of the three techniques in our group are lesser, inevitably due to a proportional percentage of the competitors with lower qualifications among the sample group. In the midst of the more unexperienced group Gyaku-Zuki punch has proven itself as a measure for muscle control after stimuli, not only revealing the shortcomings in performance for the more unprepared and thus- their subsequent improvement, but even for screening competitors with greater readiness for quick attack or effective counter-attack execution for the higher qualification levels. Not less important is the side kick Yoko-Geri, whose close value to those of Mai-Geri is an example of mastery of muscle coordination and balance of the body to the limits of our lower qualification Karate fighters without additional specialization and a guideline for improvement of rapid and fight-efficient techniques that are typical for our elite contestants.

\section{BIBLIOGRAPHY:}

Arriaza R., Leyes M. Injury profile in competitive karate: prospective analysis of three consecutive World Karate Championships. Knee Surg. Sports Traumatol. Arthrosc. 2005; 13:603-607.

Claessens A., Beunen G., Wellens R., Geldof G. Somatotype and body structure of world top judoists. J. Sports Med. Phys.Fitness 1987;1:105-113

Feld M.S., Mc Nair R., Wild S. The physics of karate. Sci. Am. 1979;4:240

Giampietro M, Pujia A, Bertini I. Anthropometric feature and body composition of young athletes practicing karate at high and medium competitive level. Acta Diabetol 2003; 40: p.145-8

Gikova M. „Complex methodology for registration and analysis of equilibrium balance and kinematic parameters in various sport techniques”, „Sport and Science” magazine No.6 / 2013 p. 34-45

Jovanović S.; Koropanovski N. Items for observing and analysis sport fight in karate. Annual of Faculty of Sport and Physical Culture in Belgrade 2002;10:85-94

Katić R, Blazević S, Krstulović S, Mulić R. Morphological structures of elite Karateka and their impact on technical and fighting efficiency. Coll Antropol. 2005 Jun; 29(1):79-84

Keogh, J., (1999). The use of physical fitness scores and anthropometric data to predict selection in elite under 18 Australian rules football team. J Sci Med Sport., 2, 125-133

Koropanovski N, Berjan B, Bozic PR, et al. Anthropometric and physical performance profiles of elite karate kumite and kata competitors. J Hum Kinet 2011; 30: 10714

Pozo, J., Bastien, G. \& Dierick, F. (2011). Execution time, kinetics, and kinematics of the mae-geri kick: comparison of national and international standard karate athletes. J Sports Sci. Nov; 29(14), 1553-1561.

Sterkowicz-Przybycień K.L Body composition and somatotype of the top of Polish male karate contestants Biol. Sport (2010); 27:195-201

Wilmore, J. H., \& Costill, D. L. (1999). Champaign: Human Kinetics. Physiology of Sports and Exercise 9, 490507.

Zagorski D., Gikova M., Penov R. (2014) Morphological characteristics of professional Shotokan karate athletes as a form of specific adaptation, $7^{\text {th }}$ International Scientific Congress „Sport, Stress, Adaptation" p. 83

CORRESPONDENCE ADDRESS:

Dimitar Zagorsky, Ass , MD

Gikova Maria, Assoc. Prof., MD, PhD

Anatomy and Biomechanics Department

Sofia 1710, Studentski grad, block 70

Telephone: (00359 2) 4014289

e-mail: dimzigzag_solo@yahoo.com 